NBER WORKING PAPER SERIES

\title{
HOSPITAL INTEGRATION AND VERTICAL CONSOLIDATION: AN ANALYSIS OF ACQUISITIONS IN NEW YORK STATE
}

\author{
Robert S. Huckman \\ Working Paper 11379 \\ http://www.nber.org/papers/w11379 \\ NATIONAL BUREAU OF ECONOMIC RESEARCH \\ 1050 Massachusetts Avenue \\ Cambridge, MA 02138
}

May 2005

The views presented in this paper do not necessarily reflect the findings of the New York State Department of Health or the New York State Cardiac Advisory Committee. I thank two anonymous referees, Malcolm Baker, Jason Barro, Richard Bohmer, Richard Caves, David Cutler, Fritz Foley, Thomas McGuire, Joseph Newhouse, Gary Pisano, Sarah Reber, David Scharfstein, Geoffrey Verter, and seminar participants the NBER Summer Institute, Harvard University, Harvard Business School, University of Rochester, Washington University-St. Louis, and Vanderbilt University for helpful comments. I also thank Rhonda O'Brien, Casey Roark, and Gene Therriault of the New York State Department of Health for their help in providing the data for this analysis. I acknowledge financial support from the Division of Research at Harvard Business School. The views expressed herein are those of the author(s) and do not necessarily reflect the views of the National Bureau of Economic Research.

(C2005 by Robert S. Huckman. All rights reserved. Short sections of text, not to exceed two paragraphs, may be quoted without explicit permission provided that full credit, including (C) notice, is given to the source. 
Hospital Integration and Vertical Consolidation: An Analysis of Acquisitions in New York State Robert S. Huckman

NBER Working Paper No. 11379

May 2005

JEL No. I1, L2

\section{$\underline{\text { ABSTRACT }}$}

While prior studies tend to view hospital integration through the lens of horizontal consolidation, I provide an analysis of its vertical aspects. I examine the effect of hospital acquisitions in New York State on the distribution of market share for major cardiac procedures across providers in target markets. I find evidence of benefits to acquirers via business stealing, with the resulting redistribution of volume across providers having small effects, if any, on total welfare with respect to cardiac care. The results of this analysis--along with similar assessments for other services--can be incorporated into future studies of hospital consolidation.

Robert S. Huckman

T17 Morgan Hall

Harvard Business School

Boston, MA 02163

and NBER

rhuckman@hbs.edu 


\section{INTRODUCTION}

Studies of industry consolidation typically assume that the specific form of integration under consideration can be neatly categorized as either horizontal or vertical. Nevertheless, in certain industries, it is difficult to classify integration in this manner. The American hospital industry—which has experienced a dramatic increase in consolidation activity over the past twenty years ${ }^{1}$ — represents one such sector. For example, consider a market in which all hospitals provide routine obstetrics, but only a few provide complex cardiac surgery. The consolidation of any two hospitals in this market would, by definition, reduce the number of firms providing obstetrics, but may leave the number of firms providing cardiac surgery unchanged. Referral patterns for cardiac surgery may change and could either increase or decrease measures of market concentration. Whether a consolidation in this market should be viewed as horizontal or vertical thus depends upon the service considered.

Most previous studies of hospital integration have relied on the horizontal model, ${ }^{2}$ suggesting that consolidation may, in theory, affect social welfare via two countervailing channels: increased market power and greater efficiency. An attractive feature of the horizontal model is that it allows one readily to infer the effect of a merger on price and cost. Horizontal consolidation, by definition, increases market concentration, so one can

\footnotetext{
${ }^{1}$ See Gaynor and Haas-Wilson (1999) for an overview of recent consolidation activity in the health care industry. Between 1980 and 1993, the annual number of hospital consolidations in the United States remained relatively stable at between 10 and 30 transactions per year (American Hospital Association, 1992; Modern Healthcare, 1994-2000). The number of transactions, however, jumped to 100 in 1994 and reached a peak of 198 in 1998 before declining to 142 in 1999 (Modern Healthcare, 19942000).

${ }^{2}$ Melnick et al. (1992), Dranove and Ludwick (1999), and Keeler, Melnick, and Zwanziger (1999) provide support for the view that increased market concentration allows hospitals to increase their prices. Noether (1988) finds that both price and quality competition are greater in less concentrated markets,
} 
estimate the impact of consolidation simply by examining the effect of increases in market concentration — typically measured by the Hirschman-Herfindahl Index (HHI $)^{3}$ on key welfare determinants such as price and cost. This approach is common in many studies of hospital competition (e.g., Noether, 1988; Melnick et al., 1992; Dranove and Ludwick, 1999; Keeler, Melnick, and Zwanziger, 1999; Kessler and McClellan, 2002).

The pure horizontal model, however, is not well equipped to explain the impact of hospital consolidation on markets for more complex services (e.g., cardiac surgery) that are often provided by only one of the two parties to a given transaction. For these services, hospital consolidation joins complements, rather than substitutes, in production, with an ambiguous impact on market concentration. Further, to the extent that hospitals providing these complex services have substantially differentiated levels of quality and cost, the transfer of cases across a fixed number of firms could have implications for welfare. For example, shifts in volume from low-quality to high-quality providers might improve overall welfare regardless of whether those shifts increase or decrease market concentration.

In this paper, I supplement existing horizontal studies by considering what I will refer to as the vertical aspects of hospital integration. I focus on the impact of consolidation on the provision of two complex cardiac procedures-coronary artery bypass graft (CABG) surgery and percutaneous transluminal coronary angioplasty (PTCA). Cardiac procedures are the subject of this study for several reasons. First, they represent a profitable and sizeable source of revenue for hospitals (Appleby, 2002;

though the impact of concentration on observed prices is not significant. Lynk (1995) suggests that consolidations may enable hospitals to lower costs by reducing the impact of variability in demand. 
Kowalczyk, 2003). Second, they require substantial fixed investments (New York State

Department of Health, 2004) in equipment and dedicated staff, creating the potential for consolidation to improve efficiency by exploiting economies of scale in production. Third, because a significant portion of patients receiving CABG and PTCA die in the hospital, the variation in average mortality among hospitals is large enough to make it a meaningful quality measure. I consider how acquisition events among hospitals in New York State between 1992 and $1999^{4}$ affected the distribution of cardiac patients across firms and the average cost and quality of care.

A small number of studies have considered the impact of consolidation on explicit quality in health care settings (e.g., Baker and Brown, 1999; Ho and Hamilton, 2000; Kessler and McClellan, 2000). ${ }^{5}$ Like prior studies that have examined the quality of cardiac care, this paper uses risk-adjusted patient mortality as the relevant measure of quality. Detailed clinical data about the pre-procedure health of every patient undergoing CABG or PTCA in New York over several years allows for more complete riskadjustment than has been used in most previous studies.

\footnotetext{
${ }^{3}$ The HHI for a given market is calculated as the sum of the squared market shares across all firms serving a given market. Kessler and McClellan (2000) outline the reasons why the use of simple HHI measures may lead to biased estimates of the effects of competition in hospital markets.

${ }^{4}$ This number represents a lower bound for the total number of consolidations that occurred in New York between 1992 and 1999. All transactions occurring after 1993 were verified using the annual survey of hospital merger activity conducted by Modern Healthcare. For 1992 and 1993, consolidations were identified on the basis of public news reports identified by searches of the LEXIS database.

${ }^{5}$ Ho and Hamilton (2000) suggest that, given the fixed or quasi-fixed nature of hospital prices for many services, hospitals could theoretically use lower quality as a means of lowering costs and increasing profits following consolidation. Their empirical analysis finds that consolidations among California hospitals in the early 1990s were associated with increased readmission rates for heart attack patients and higher rates of early discharge for newborns. Nonetheless, they find no significant effects on mortality for heart attack or stroke patients. Kessler and McClellan (2000) examine the impact of hospital competition on the quality and cost of heart attack patients. They find that, before 1991, competition was associated with higher costs and higher quality of care. In the early 1990s, however, competition was associated with unambiguous welfare effects (i.e., lower costs and higher quality). Baker and Brown (1999) find that increased HMO penetration leads to consolidation among mammography providers. They also find that increased HMO activity is associated with lower costs and longer waiting times for mammography appointments, but not with reductions in health outcomes.
} 
Acquisitions that shift procedure volume from non-acquirers to acquirers are a form of "business stealing" (Mankiw and Whinston, 1986). I find evidence of such activity with respect to cardiac care. In particular, defining the "acquirer" as the hospital offering complex cardiac services, I find that consolidations are correlated with an increase in the acquirer's share of cardiac procedures originating from the primary market of the target. I consider the welfare implications of this business stealing by decomposing its effect on average quality and cost into two components: simple redistribution and volume-related changes in performance. Simple redistribution captures the impact of moving volume between hospitals with different levels of hospital-specific quality or cost. Volume-outcome effects may occur to the extent that consolidations increase volumes at some hospitals and decrease them at others. Such volume changes may affect the average quality and cost of care at both acquiring hospitals that gain volume and competing facilities that lose it. Though results differ somewhat for CABG and PTCA, hospital consolidation appears to have had little impact on average cost and quality of major cardiac procedures in New York.

\section{THE POTENTIAL EFFECTS OF HOSPITAL CONSOLIDATION}

\section{Private Incentives for Business Stealing and Increased Volume}

One can imagine several reasons for the pursuit of acquisitions. These include increased volume or market share, higher prices, ${ }^{6}$ and synergies unrelated to quantity. ${ }^{7}$ The first of these is the focus of this analysis.

\footnotetext{
${ }^{6}$ One possible effect of hospital consolidation is an increase in price or price-cost margins resulting from greater market concentration (Melnick et al., 1992; Dranove and Shanley, 1995; Keeler,
} 
A 2003 news article on innovations in cardiac care noted, "For three decades, open heart surgery has been the most profitable service at many hospitals” (Kowalczyk, 2003). It continues by noting that average margins for CABG procedures have traditionally exceeded $40 \%$. The lucrative nature of cardiac procedures has made it attractive for hospitals to attempt to steal market share from competitors. Barro and Cutler (2000) speculate that large “downtown” hospitals may buy small "suburban” hospitals to increase the share of patients traveling from the suburbs to the downtown facility.

Market transactions are an alternative to vertical integration to increase sales. In health care, however, such market transactions are labeled "kickbacks" and are subject to legal and professional sanction. For example, it is fraudulent for hospitals to sign contracts with independent physicians that are construed as involving the "purchase" of patient referrals. Such contracts are viewed as creating potential conflicts of interest for physicians who are expected to serve as agents for their patients. Nevertheless, hospitals are typically allowed to employ physicians directly.

Melnick, and Zwanziger, 1999). Unfortunately, New York collects data at the patient level only on gross charges, not on actual prices paid. As a result, this study is not able to consider the effects of market concentration on price. Given the unique regulatory environment in New York during much of the sample period, however, one could argue that these effects were likely small. Until January 1997, hospital rates for inpatients with commercial (i.e., non-HMO and non-government) insurance were administered by a statewide pricing formula. In addition, Medicare inpatient rates were set by the federal government under the Prospective Payment System (PPS) adopted in 1983. As a result of the New York and federal regulations, nearly 85\% of the inpatient admissions involving CABG or PTCA in New York during 1996 were covered under some form of price regulation. This regulatory structure should reduce concerns about price-related welfare effects resulting from hospital consolidation, especially in the first half of the sample.

${ }^{7}$ For example, acquisitions may increase the degree of formal or informal communication between physicians in the target market and those practicing at acquiring hospital. In addition, consolidation allows each hospital to benefit from the administrative skills (e.g., managerial expertise) found at the other facility. Finally, many target hospitals - which are noticeably smaller than acquirers along several dimensions (Table 2) — may face financing constraints that reduce their ability to invest in new clinical services. By linking small targets with larger acquirers - who likely have higher internal cash flows and fewer borrowing constraints-acquisitions may serve to decrease the financing costs for targets. The synergies described above, however, are not easily captured by the administrative and financial data available at the 
The corporate strategy literature (Wernerfelt, 1984; Dierickx and Cool, 1989; Peteraf, 1993; Capron, 1999) notes that firms integrate to compensate for incomplete markets for resources, such as brand names, management expertise, or referrals. In the case of hospital integration, both acquirers and targets may hold critical resources for which markets are incomplete. Through integration, the acquirer might gain access to the target's resource of a close attachment to local patients and physicians; the target might gain access to specialized technology, the quality reputation of the acquirer, and potentially valuable contracts with managed care payors.

\section{Welfare Implications of Business Stealing}

Acquisitions can change the average quality and cost of care. With respect to either quality or cost, these effects can be decomposed into two parts. First, business stealing results in the movement of patients between hospitals with different levels of underlying quality or cost. For example, patients may move from hospitals that have highly-skilled cardiac surgeons to those that have less-skilled surgeons. I refer to this impact of mergers as "simple redistribution".

Changes in volume at individual hospitals also can affect average quality and cost, creating a second channel through which acquisition-related business stealing can impact welfare. Previous studies have identified a negative relationship between annual procedure volume—at either the hospital or physician level—and mortality rates for

hospital level. As a result, I am unable to provide an empirical test of this theoretical motivation for acquisition. 
CABG and PTCA patients. ${ }^{8}$ Similar effects may also be present with respect to the average cost of care. Moving volume from one hospital to another may thus improve performance at the expanding hospital while decreasing it at the shrinking facility.

\section{CARDIAC PROCEDURES}

\section{A Brief Summary of Cardiac Procedures}

The path for a typical cardiac patient through the medical system begins at a hospital or physician's office with a condition that may be either emergent, such as an acute myocardial infarction, or chronic, such as ischemic heart disease. The physician decides whether to prescribe a diagnostic cardiac catheterization — which is performed at a hospital on either an inpatient or outpatient basis—-to look for arterial blockage. As an alternative to catheterization, the physician may prescribe medical treatment of the patient's condition. For those patients undergoing catheterization, the physician recommends one of three broad options—-no further surgical treatment, CABG, or PTCA.

The CABG and PTCA options- - together referred to as revascularizationsinvolve additional procedures for the patient. CABG is an invasive surgical procedure that involves taking a section of artery, typically from the patient's leg, and grafting it to create a bypass of the blockage in the coronary artery. It requires the opening of the patient's chest and relies on a heart-lung bypass machine to perform the functions of the heart during the grafting process. In comparison, PTCA involves the threading of a balloon device to the point of blockage. The balloon is inflated to expand the artery and

\footnotetext{
${ }^{8}$ Luft, Bunker, and Enthoven (1979), Showstack et al. (1987) and Hannan et al. (1991) consider these relationships for CABG, while Hannan et al. (1997) and Ho (2000) examine them with respect to PTCA.
} 
restore blood flow. PTCA, therefore, is less traumatic than CABG, as PTCA patients avoid the substantial chest incision and arterial reconstruction that are integral parts of the CABG procedure. PTCA patients, however, run the risk of restenosis, or the return of blockage to the artery. ${ }^{9}$

\section{The Economics of Cardiac Procedures}

Cardiac procedures have high fixed costs in the form of specialized equipment and dedicated staff. Catheterizations and PTCAs are performed in dedicated catheterization laboratories. CABG procedures are performed in operating rooms thatwhile sometimes available for other procedures - typically are dedicated to cardiac surgery. Between 1996 and 2000, the State of New York received 51 applications from hospitals that intended to build or renovate their catheterization laboratories. ${ }^{10}$ The average cost for these projects was $\$ 2.68$ million with a standard deviation of $\$ 1.65$ million (New York State Department of Health, 2004). During the same period, the state received seven applications from hospitals that aimed to initiate cardiac surgery programs. ${ }^{11}$ The mean cost of these programs was $\$ 14.05$ million with a standard deviation of \$20.7 million. These figures do not include the cost of nurses and technologists who are typically dedicated to a catheterization lab or a cardiac surgery program. When combined with limitations on hospital investment imposed by many states, these high fixed and quasi-fixed costs enable only a portion of hospitals to offer CABG and PTCA.

\footnotetext{
${ }^{9}$ In recent years, the problem of restenosis for PTCA patients has decreased due to the development of stents, which are small metal inserts that prop open the artery after angioplasty.

10 To keep projects comparable, this group excludes any applications that included services other than cardiac catheterization.
} 
Cardiac procedures are profitable for hospitals in New York, both on average and at the margin. The average Medicare reimbursement for an admission involving CABG in New York was approximately $\$ 33,700$ in 1997; the analogous figure for PTCA was roughly $\$ 15,200$ (Table 1). ${ }^{12}$ The average cost per Medicare admission in 1997 was $\$ 31,700$ for CABG and $\$ 13,100$ for PTCA. These figures imply an average profit of $\$ 2,000$ (6\%) for CABG and \$2,100 (14\%) for PTCA. Though exact revenue data are not available for non-Medicare patients, I use the actual distribution of patients across the various payor types (i.e., Medicare, commercial, and Medicaid or HMO) in 1997 and estimates of the average reimbursement rates for non-Medicare providers to arrive at an average profit per case across all payer types in 1997 . These figures are $\$ 3,900$ for CABG (Column 2) and \$2,700 for PTCA (Column 3). ${ }^{13}$ Multiplying these profit-percase figures by the number of patients per hospital receiving CABG and PTCA, respectively, illustrates that the average hospital performing CABG and PTCA in New York in 1997 generated net revenues of \$33.3 million (9.6\% of total hospital net revenue) and operating profit of $\$ 4.7$ million (16\% of total hospital net income) solely from patients receiving either CABG or PTCA.

Due to the large fixed costs associated with CABG and PTCA, the marginal profitability of these procedures substantially exceeds their average profitability. Later, I

${ }^{11}$ This figure and that for catheterization represent the number of applications submitted, not the number approved by the state.

${ }_{12}$ The revenue-per-admission figures are based on the fact that New York hospitals received and average of \$6,164 per case-mix adjusted Medicare case in 1997. The average case-mix index across all Medicare CABG patients in New York was 5.47 in 1997, resulting in the estimated revenue figure of $\$ 33,700(\approx \$ 6,164 \times 5.47)$ per case. For PTCA, the average case-mix index was 2.47 . To correct for the small number of cases with unrealistically low reported charges, these average case mix figures exclude CABG cases with reported charges of less than $\$ 5,000$ (roughly $1.2 \%$ of CABG cases) and PTCA cases with reported charges of less than $\$ 2,500$ (roughly 3.4\% of PTCA cases).

${ }^{13}$ A national estimate, reported in 2002, for the average profit for a CABG procedure was $\$ 6,800$ per case (Appleby, 2002). This figure differs from that in this study due to the fact that it is based on more recent data from a wider geography than just New York State. 
estimate the marginal cost for an admission involving CABG in 1997 to be approximately $\$ 26,700$, implying a marginal profit of $\$ 6,200$. For PTCA, the estimated marginal cost was $\$ 9,800$ and marginal profit was $\$ 4,900 .{ }^{14}$ Most hospitals thus are in a position of seeking to expand their volume of cardiac procedures.

\section{ACQUISITIONS IN NEW YORK STATE, 1992-1999}

\section{Definitions}

For the purposes of this study, a "consolidation” is defined as any transaction that involves delegating the key decision-making rights of two or more hospitals to a single board. The universe of consolidations thus includes full asset mergers, holding companies involving substantially all of the operations of multiple hospitals, and any other "active parent” relationships. This definition of consolidation excludes less-formal relationships such as joint marketing agreements for particular services (e.g., cardiac care, oncology) and academic affiliations. Consolidations can be classified further as either "acquisitions" or "mergers" depending on the characteristics of the hospitals involved. An acquisition joins two or more parties that are asymmetric with respect to size or services offered. Alternatively, mergers bring together parties that are roughly similar with respect to size and services.

This paper focuses on acquisitions and defines acquirers and targets by their cardiac service offerings. Specifically, an acquirer is a hospital that offers CABG and

14 The marginal cost estimates are based on the estimated effect of $\ln$ [annual CABG (PTCA) admissions] for hospital $h$ on average cost per CABG (PTCA) admission at hospital $h$ (see Equation (3)). The marginal cost estimates are calculated by dividing the growth in total costs due to a $1 \%$ increase in volume by the absolute magnitude of the $1 \%$ volume increment. 
PTCA and was involved in an acquisition between 1992 and $1999 .^{15}$ A target is a hospital that was involved in an acquisition between 1992 and 1999 and did not offer CABG or PTCA prior to consolidation. Acquisitions integrate hospitals that possess fundamentally different capabilities with respect to cardiac procedures and, as a result, do not necessarily result in a reduction in the number of firms providing these services in a given market. In fact, during the time period studied, none of the CABG or PTCA programs in New York State were closed. ${ }^{16}$

Based on the definitions above, over $60 \%$ of the consolidations in New York between 1992 and 1999 -28 out of $45^{17}$ — were acquisitions (Figure 1). In six of the 17 mergers, both hospitals offered CABG and PTCA, and, in the remaining 11, none of the parties offered CABG or PTCA prior to merger. These two types of mergers are referred to as “big-big” and “small-small”, respectively, in Figure 1.

\section{Universe of Transactions}

The universe of transactions for this study includes the 28 acquisitions involving New York hospitals between 1992 and 1999. These 28 transactions corresponded to the acquisition of 35 target hospitals by 16 acquirers. The year of a given transaction is defined as the one in which it legally closed. In cases where the date of closure is not

\footnotetext{
15 This range of dates reflects the fact that minimal acquisition activity occurred in New York prior to 1992.

${ }^{16}$ The CABG program at one facility in a multi-hospital system was moved to a different hospital in that system in 1993. Nonetheless, the number of statewide CABG programs was not affected by this transfer.

17 This number represents a lower bound for the total number of consolidations that occurred in New York between 1992 and 1999. All transactions occurring after 1993 were verified using the annual survey of hospital merger activity conducted by Modern Healthcare. For 1992 and 1993, consolidations were identified on the basis of public news reports identified by searches of the LEXIS database.
} 
available, the year in which both hospital boards approved the consolidation is used as the year of the transaction. ${ }^{18}$

Table 2 provides descriptive statistics for 1992 — the first year of discharge data used in this study — for the hospitals in the sample of acquisitions. On average, acquirers were more than twice as large as targets in terms of inpatient beds and hospital days and at least three times as large in terms of net revenue and operating expenses. With respect to cardiac procedures, the average acquirer performed nearly 650 CABG and 470 PTCA procedures in 1992.

\section{Primary Hospital Markets}

Defining hospital markets is an issue that has received significant attention in the literature (see Gresenz, Rogowski, and Escarce (2004) for a recent discussion). Some studies use fixed radii around a hospital (e.g., Shen, 2003), while others have defined markets based on variable radii around a hospital to capture a fixed percentage of its admissions (e.g., Phibbs and Robinson, 1993). Defining markets based on observed admissions may be subject to concerns of endogeneity with respect to variables of interest, such as prices, quality, or market volume (Kessler and McClellan, 2000).

I use a variant of the variable-radii approach to define the primary markets of each target hospital in my sample. The primary market of a target includes any zip codes that accounted for at least five percent of a hospital's inpatient admissions in the base year of

\footnotetext{
${ }^{18}$ The dates of transactions were determined using the following sources: searches of the LEXIS/NEXIS database using the names of potential acquirers; the annual survey of hospital consolidation activity in the United States conducted by Modern Healthcare for each year after and including 1994; the Greater New York Hospital Association's annual surveys of health care systems in New York for each year after and including 1993; and author’s correspondence with hospital executives.
} 
the study (i.e., 1992) ${ }^{19}$ I use this simple approach to market definition because I am identifying the impact of mergers based on longitudinal analysis of an acquirer's market share within a given target market. The goal of my analysis is to identify an area that represents the "historic" market for a target hospital and ask how the share of cardiac cases traveling to the acquirer from that market changes after an acquisition.

\section{DATA}

A critical reason for using New York as the setting for this study is the high quality of data—both administrative and clinical—available for cardiac patients. The Statewide Planning and Research Cooperative System (SPARCS) database provides discharge-level records on every inpatient hospital case in the state. ${ }^{20}$ This database includes detailed information about the patient (e.g., age, race, sex, insurance status, zip code of residence), providers (e.g., hospital and physician identifiers), diagnoses, and procedures performed. In 2000, this database included over 2.3 million discharges, the smallest total for any of the nine years—1992 through 2000—analyzed in this study.

The information from SPARCS is supplemented by discharge-level data for CABG patients from New York's Cardiac Surgery Reporting System (CSRS) and for PTCA patients from the state's Coronary Angioplasty Reporting System (CARS). These data provide additional clinical detail on each patient undergoing revascularization

\footnotetext{
${ }^{19}$ To provide for a slightly larger market area, I repeat the base regressions using markets that include any zip code that accounted for at least three percent of a hospital's inpatient admissions in 1992. The results on share redistribution reported later in the paper are robust to this change in market definition.

${ }^{20}$ The SPARCS data were obtained following approval from the Data Protection Review Board of the New York State Department of Health. For the multivariate analysis later in the paper, I exclude those records that did not receive a Diagnosis Related Group (DRG) code. In 1992, 84,581 admissions (3.2\% of
} 
between 1991 and 1996 for CABG and 1993 and 1995 for PTCA. The annual number of CABG procedures in the CSRS data ranges from a low of 14,944 in 1991 to a high of 20,078 in 1996; ${ }^{21}$ for PTCA, these figures vary from 16,804 in 1993 to 21,707 in 1995.

The cost regressions and welfare calculations appearing later in this paper draw upon data from Medicare Prospective Payment System (PPS) cost reports. These data provide cost-to-charge ratios for each hospital performing CABG or PTCA in New York for each year between 1992 and 1998.

\section{RESULTS}

\section{Business Stealing}

To test for business stealing, I determine whether acquisitions are associated with changes in the shares of acquirers serving the primary markets of target hospitals. The identification of acquisition-related changes in market share comes from the staggered timing of individual transactions. I estimate the following specification using data from all zip codes that are within the primary market of at least one target hospital:

$$
A C Q \_S H A R E_{i t}=\alpha_{i}+\gamma_{3 t}+\delta_{k} D_{i t}+\beta Z_{i t}+\varepsilon_{i t}
$$

$A C Q \_S H A R E_{i t}$ represents the market share of the relevant acquirer for zip code $i$ in year $t$. If zip code $i$ is in the primary market of multiple target hospitals, $A C Q \_S H A R E_{i t}$ is the

total) did not have a DRG; in 1993, this figure was 117,135 (4.6\%). After 1993, all records in the SPARCS data received a DRG. 
combined share of all acquirers for that zip code. ${ }^{22}$ The above specification is estimated separately for CABG and PTCA.

The key independent variables are included in $D_{i t}$, the vector of indicators for "year relative to acquisition.” Each of the individual indicators, referred to as $d_{i t}^{k}$, takes a value of one if zip code $i$ is in the primary market of a target hospital that: 1) was acquired between 1992 and 1999 and 2) is $k$ years away from the date of acquisition in year $t .{ }^{23}$ Because I am interested in identifying changes in primary markets after consolidation, I test whether each $d_{i t}^{k}$ coefficient is significantly different from that for the year of acquisition, $d_{i t}^{0}$, or the year immediately preceding acquisition, $d_{i t}^{-1} .^{24}$ The pre-transaction dummy variables serve to distinguish acquisition-related changes from the simple continuation of existing trends that may be unrelated to consolidation. Zip-code fixed effects, $\alpha_{i}$, are included to control for time-invariant characteristics of given areas that might affect the market share of specific providers. The vector $Z_{i t}$ includes additional demographic controls. These include Medicaid, HMO, and female patients, respectively, as a percentage of patients receiving a particular cardiac procedure in a given zip code. These variables control for the possibility that certain providers may be more likely to target particular socioeconomic, payor, or gender categories. In addition, $Z_{i t}$ includes the percentage of patients from a given zip code in each of several

${ }^{21}$ The CSRS data includes information only for "isolated" CABG procedures. A CABG is "isolated" when it occurs on a patient who does not receive any other major heart surgery (e.g., valve or other heart procedures) during the same admission (New York State Department of Health, 1998).

${ }^{22}$ Seventy-nine percent of the zip codes that are in the primary market of at least one target are in the primary market of only one target, $20 \%$ are in the primary market of two targets, and $1 \%$ are in the primary market of three targets.

${ }^{23}$ The index $k$ is negative for years prior to merger and assumes the following values: $\leq-4,-3,-2,-$ $1,0,1,2,3$, and $\geq 4$. 
age categories $^{25}$. These categories allow for the possibility of a non-linear relationship between patient age and the market shares of particular types of hospitals.

Fixed effects for calendar time, $\gamma_{3}$, are included to control for changes in the average share of acquirers over time. For example, if, on average, acquirers increased their quality more than other hospitals during the period studied, one would not be surprised to see their shares growing in target areas over time even in the absence of acquisitions. Including single-year fixed effects concurrently with fixed effects for zip code and year-relative-to-acquisition, however, creates problems with respect to identification. In fact, the identification in such a model would come only from those zip codes that are in the primary market of more than one hospital and the "collection points"-four or more years before or after acquisition-among the year-relative-toacquisition indicators. As an alternative to fixed effects for each year, I use indicators for three-year periods — 1992 to 1994, 1995 to 1997, and 1998 to 2000 — to capture the impact of calendar time on the share to acquirers.

Table 3 shows that acquisitions increase the CABG and PTCA market shares of acquiring hospitals in primary markets of their targets. Column 1 illustrates that the CABG share to acquirers increases by a total of 5.0 percentage points from Year 0 to Year 3. The magnitude of this increase-which is calculated by subtracting the value of the Year 0 coefficient from the Year 3 coefficient $[0.027-(-0.023)]$ - is $18 \%$ of the weighted average share to acquirers prior to acquisition (27.6\%) and is significant at the

${ }^{24}$ Comparisons with both the year of acquisition and the year before acquisition are used because the official merger date is measured by the year in which the transaction closes. Changes in market share, however, may begin after the deal is announced but before it closes.

${ }^{25}$ The age categories include: less than 50, 50-59, 60-64, 65-74, 75-84, and greater than or equal to 85 . 
$1 \%$ level. ${ }^{26}$ The share increase for four or more years after acquisition is similar in magnitude at 4.8 percentage points and is significant at the $5 \%$ level. Though not significant at conventional levels, the share gains for the first and second years following acquisition do suggest an increasing trend. The results for PTCA (Column 2) are similar to those for CABG and suggest an increase of 6.0 percentage points (24\% relative to the weighted average share in the sample) by Year 3 and 6.3 percentage points for Year 4 and beyond. ${ }^{27}$ Figure 2 presents these results graphically, normalizing acquirer share to zero in Year 0.

As mentioned above, for many acquisitions, I was only able to confirm the year in which the transaction was completed rather than the year in which it was announced. Nevertheless, it is possible that referral patterns may begin to change after a merger is announced but before it closes. I thus test the significance of share changes relative to Year -1 rather than Year 0. Measuring changes in this manner for CABG suggest slightly larger and statistically significant changes for Year 3 and Year 4 and beyond. In addition, it shows that the change by Year 2 is also significant at the 5\% level. For PTCA, the changes for Year 3 and beyond are slightly smaller in magnitude, though still significant at conventional levels.

A few features of these results merit particular attention. First, despite the inclusion of zip-code-level fixed effects, the Durbin-Watson statistics for the regressions in Table 3 suggest that some correction for correlation in the error terms may be required.

\footnotetext{
${ }^{26}$ This weighted-average share is calculated using all zip-year observations prior to the year of the acquisition affecting a given zip code. In cases where a zip code is in the primary market of two or more hospitals, this figure is calculated based on the date of the first acquisition affecting that area.

${ }^{27}$ The dependent variable in the basic specification is limited to values between zero and one. To address the impact of this restriction, I re-estimate the regressions using the logistic transformation of the acquirer's market share in a given zip code. That is, the dependent variable in these regressions becomes
} 
To address this issue, the standard errors in all models are clustered by target market to address any possible lack of independence in the error terms (i.e., remaining after the zipcode fixed effects) for zip codes within the same target market. ${ }^{28}$

A second potential critique of these results is that the occurrence of acquisitions may be endogenous. For example, acquirers may use these transactions to solidify their presence in markets where they are already gaining share. In such a case, a postacquisition increase in share in a target market may simply represent the continuation of pre-acquisition trend. Nevertheless, the coefficients on the pre-acquisition indicators reveal that there is no significant pre-acquisition trend in market share and, therefore, reduce concerns about the effects of such endogeneity.

A third potential critique of these results is that they may be influenced by the unbalanced panel of observations. This might be the case if certain acquisitions are included in the sample for their post-acquisition years, but are not included in their preacquisition years and vice-versa. For example, because the data range from 1992 to 2000, a transaction that occurred in 1993 will not have observations for two, three, and four or more years prior to acquisition. Similarly, a transaction occurring in 1998 will not have observations for three or four or more years after acquisition. While the data include at least one year of post-acquisition observations for 28 transactions and two

$\operatorname{LTSHARE}_{i t}=\ln \left(A C Q \_S H A R E_{i t} /\left(1-A C Q \_S H A R E_{i t}\right)\right)$. The estimates are qualitatively similar to those in the basic specification.

${ }^{28}$ I also estimate these models with the assumption of an AR(1) error structure within zip codes and heteroskedasticity across zip codes. The results of this AR(1) estimation are qualitatively similar to those in Table 4, though there is some evidence of a decline in market share to acquirers prior to acquisition. The AR(1) model, however, does not account for potential correlation across zip codes within a given target market, as is the case with the clustered standard errors reported in Table 3 . The clustered models, while not efficient, are robust to any type of within-group correlation. Given the support for the use of clustering over parametric assumptions in similar situations (Bertrand, Duflo, and Mullainathan, 2004), I use the results with standard errors clustered by target area for this analysis. 
years for 23, there are three (four-plus) years of observations for only 19 (16) acquisitions.

To address the impact of the unbalanced panel, I re-estimate (1) on a sample that includes only those zip codes with data in each period from Year -2 to Year 2. The results of these regressions appear in Columns 1 (CABG) and 3 (PTCA) of Table 4. To ensure balance, these regressions include only those zip codes that were in the primary market of a single acquisition between 1992 and 1999. The resulting panels include observations from roughly $18 \%$ of the zip codes in the unbalanced CABG (PTCA) regression in Table 3.

The regressions provide strong support for the hypothesis of acquisition-related increases in the average share of procedures going to acquirers. Relative to Year 0, CABG share increases by roughly 7.4 percentage points (46\% relative to the $16.1 \%$ weighted average share for the balanced sample prior to acquisition) by Year 2 (Column 1). Similarly, PTCA share rises by 13.9 percentage points (Column 3). As in the unbalanced panel, there is no significant pre-acquisition trend in share to acquirers. The results in Columns 2 and 4 extend the balanced panel to three years following acquisition and illustrate that the increase in market share continues beyond Year 2. The three-year increase for CABG (PTCA) is greater than 8.7 (19.2) percentage points. The dashed lines in Figure 2 show these results graphically.

The balanced panels that extend to three years after acquisition show some evidence of share increases prior to the year of acquisition, particularly for PTCA. Nevertheless, the growth in share from Year 0 to Year 2 is over twice the magnitude of 
the growth from Year -2 to Year 0. As noted above all of the balanced-panel results must be qualified by the restricted samples on which they are estimated.

\section{IMPLICATIONS FOR QUALITY AND COST}

I next consider the effect of acquisitions on the quality and cost of care. A common measure of the quality of CABG and PTCA procedures is the risk-adjusted mortality rate (RAMR). Previous studies have used administrative covariates, such as age, race, gender, and the number of comorbidities as the basis for the risk-adjustment of outcomes (Ho and Hamilton, 2000). New York’s CSRS and CARS data provide additional clinical covariates for each patient. This information, such as the patient's ejection fraction and whether he or she has a history of diabetes or myocardial infarction, allows for better risk-adjustment. New York State uses this CABG and PTCA data to create risk-adjusted mortality rankings for individual physicians and hospitals in the entire state. These rankings have been released in annual public reports (e.g., New York State Department of Health, 1998) each year since 1993 (for CABG) and 1995 (for PTCA).

To determine the effect of acquisitions on total mortality, I estimate the following specification:

$$
M O R T_{i h t}=\delta_{h}+\gamma_{t}+\beta_{d} \ln \left(x_{h, t-1}\right)+\varphi M_{i h t}+\varepsilon_{i h t}
$$


$M O R T_{i h t}$ is an indicator that assumes a value of one if patient $i$ died during his or her stay in hospital $h$ following a procedure in year $t . x_{h, t-1}$ is the volume of relevant procedureseither CABG or PTCA—performed at hospital $h$ in year $t$. I use the lagged value of annual volume to reduce the impact of possible endogeneity associated with using volume in the current year. The semi-logarithmic form chosen for (2) is common in the volume-outcome literature (Luft, Hunt, and Maerki, 1987; Farley and Ozminkowski, 1992). ${ }^{29} \delta_{h}$ is a vector of hospital fixed effects, $\gamma_{t}$ is a vector of fixed effects for year, and $M_{i h t}$ is a vector of demographic and clinical controls for each patient. I estimate (2) separately for CABG and PTCA. A list of the controls included in each equation appears in the Appendix. ${ }^{30}$

A specification analogous to (2) is used to estimate the risk-adjusted cost of CABG and PTCA cases. The form of this equation is:

$$
\operatorname{COST}_{i h t}=\mu_{h}+\gamma_{t}+\beta_{c} \ln \left(x_{h, t-1}\right)+\varphi R_{i h t}+\varepsilon_{i h t}
$$

Similar to (2), the above equation includes fixed effects for hospital $\left(\mu_{h}\right)$ and year $\left(\gamma_{t}\right)$ as well as a vector, $R_{i h t}$, which contains both a linear and quadratic control for patient age. $C O S T_{i h t}$ represents the estimated cost of patient $i$ 's entire admission, regardless of whether that patient received procedures other than CABG or PTCA. This variable is

${ }^{29}$ To test the fit of the semi-logarithmic form for the mortality regression, I re-estiamted this equation using: 1 ) only a linear volume term and 2) linear and quadratic volume terms. The adjusted $\mathrm{R}^{2}$ were identical to three digits in all three specifications. Similar results were obtained for various forms of the PTCA mortality model. Given the use of the semi-logarithmic form in prior studies-as well as the belief that volume-outcome effects taper at higher volumes-I rely on the semi-logarithmic sepcficiation for this analysis.

${ }^{30}$ Because length of stay may be an endogenous determinant of mortality, it is not included in the regressions presented in this paper. Nevertheless, including length of stay does not have a material effect on either the coefficient on lagged volume or the relative values of the hospital-specific intercepts. 
estimated because New York provides data only for gross charges—not actual cost or prices paid—at the level of the individual patient. To estimate the cost per patient admission, I calculate the cost-to-charge ratio for each hospital-year using data from the Medicare PPS Cost Reports. For a given hospital, the cost-to-charge ratio is total operating expense divided by gross patient revenues. The average value of this ratio across the nine acquirers in the sample $-77.1 \%$ —is roughly similar to the average value of $72.9 \%$ for targets (Table 2).

This single ratio does not capture the heterogeneity in cost-to-charge ratios across various clinical departments within a given hospital (e.g., the cost-to-charge ratios for cardiac care may be quite different from those for general medical care). To the extent that each hospital's composition of low-margin and high-margin services differs, the use of a single cost-to-charge ratio for each facility may hinder comparison of cardiac costs across facilities. Limiting this analysis only to hospitals that provide CABG and PTCA likely provides greater homogeneity in case mix across sample hospitals than that found in the entire cross section of New York facilities. Nevertheless, the remaining heterogeneity across sample hospitals cannot be easily measured or controlled for using the data available for this study.

For several reasons, the mortality and cost regressions are run on patient populations that overlap significantly, but are not identical. First, the CSRS and CARS data are not available for the same years as the SPARCS data. ${ }^{31}$ In addition, a small

${ }^{31}$ The CABG mortality results are based on CSRS data for all cases from 1992 to 1996 (with 1991 used to generate lagged volumes) and the PTCA regressions include data for 1994 and 1995 (with 1993 data used to generate lagged volumes). These were the only years of data available as of the date this study was initiated. The cost regressions - which rely on the patient-level charge information found in SPARCS but not in the CSRS and CARS database-include CABG and PTCA patients for the six-year period from 1993 to 1998 (with 1992 used to generate lagged volumes). Given differences in encryption methodologies, the CSRS, CARS, and SPARCS data could not be linked for this study, so clinical 
percentage of cases in the SPARCS data have unrealistically low reported charges; I exclude CABG cases with reported charges of less than $\$ 5,000$ (roughly $1.2 \%$ of CABG cases) and PTCA cases with reported charges of less than $\$ 2,500$ (roughly 3.4\% of PTCA cases) from the cost regressions. These cases may or may not be included in the CSRS and CARS data, and, hence, in the mortality regressions.

Table 5 reports the volume-outcome effects with respect to both mortality and cost. For CABG, a 10\% increase in a hospital's lagged CABG volume is correlated with a 0.09 percentage point decrease in its risk-adjusted mortality rate. This 0.09 percentagepoint decrease represents a change of 3.3\% relative to the statewide mortality rate for CABG of $2.66 \% .^{32}$ In contrast, the PTCA regressions suggest a positive, but insignificant, relationship between lagged hospital volume and mortality. The PTCA results must be qualified, however, as they are based on only two years of data. Further, mortality is less common for PTCA than for CABG, making outcomes noisier for the former procedure. The welfare calculations later in this section assume no volumerelated quality effects for PTCA. This assumption is conservative in light of other studies that have found a volume-outcome relationship for PTCA that is in the same direction as that for CABG (Hannan et al., 1997; Ho, 2000).

The cost regressions find that costs fall as volume increases. These effects are small, but highly significant, for both CABG and PTCA. For CABG, a 10\% increase in volume leads to a $\$ 230$ decrease in the average cost per case ( $0.8 \%$ relative to the average of $\$ 28,000$ per case across all years and zip codes in the sample). For PTCA, a similar

covariates could not be incorporated into the cost regressions. As a result, the risk-adjustment for cost is more limited than that for mortality.

${ }^{32}$ Represents the statewide, in-hospital mortality rate for CABG in New York for the period from 1991 to 1996. 
increase in volume leads to a $\$ 220$ decrease in cost (1.9\% relative to the average of $\$ 11,800$ per case across all years and zip codes).

The movement of market share between hospitals can affect total welfare via two channels: simple redistribution and volume-outcome effects. Table 6 summarizes the effects on cost and quality for CABG and PTCA across all of the acquisitions in this study. Unless otherwise noted, these effects are based on changes that occur by Year 3. To determine the values in the "Simple Redistribution" section of the table, I re-estimate (1) using the volume-weighted, hospital-specific intercepts for mortality $\left(\delta_{h}\right)$ and cost $\left(\mu_{h}\right)$ from (2) and (3), respectively, as the dependent variable. For the most part, share redistribution has no significant effect on either CABG mortality or cost. The one exception is the reduction in mortality of 3.5 deaths in the two-year balanced panel, though this result is based on data from only 36 zip codes.

To measure volume-outcome effects, I draw upon the market share results from Table 3. For the average target market in the year 2000, this share increase translated into approximately seven additional CABG cases per year per target acquired. Given the semi-logarithmic form of the volume-outcome relationships, the net effect of this movement depends on the total number of patients at each type of hospital prior to an acquisition. In 2000, hospitals that were acquirers during the study period had an average of 983 CABG cases. To simplify the calculations, I divide the universe of hospitals that "lost" volume into two groups: hospitals that made acquisitions in other markets but not in the market in question (i.e., non-local acquirers) and hospitals that did not make any acquisitions (i.e., non-acquirers). The former hospitals performed an average of 825 CABG procedures in 2000, while the latter performed 614. Regardless of whether the 
full sample or balanced panels are used, the volume-outcome effects suggest small declines in mortality and cost at acquirers that are almost entirely offset by increases at non-local acquirers and non-acquirers. The aggregate impact of these volume-outcome effects is, therefore, very small.

These small overall volume-outcome effects are not unexpected given the magnitude of cases moving between hospitals relative to the overall size of their cardiac programs. For example, the average acquirer adds roughly seven CABG procedures per year per acquisition from seven competing facilities, while each non-acquirer loses one procedure per year per acquisition. Given the total volume of CABG procedures being performed by the hospitals in this sample (i.e., 600 to 1000), it is quite likely that this relatively small movement of volume occurs near the "flat" of the volume-outcome curve. While these volume-outcome effects are not substantial with respect to mature procedures, such as CABG, such effects could be more meaningful for procedures that are early in their lifecycle or for procedures where acquirers and non-acquirers have dramatically different initial volumes of activity. Repeating this methodology on technologies that are earlier in their life cycle represents an area for future investigation. The bottom half of Table 6 presents analogous welfare calculations for PTCA. These figures are more sensitive to the assumptions of the analysis than is the case for CABG. For example, the unbalanced panel suggests an increase in mortality of roughly four deaths per year in New York due to the redistribution of patients to hospitals with relatively weaker PTCA programs. The balanced panel results, however, show wideranging outcomes. The two-year balanced panel shows trivial welfare improvement (due 
to slightly reduced costs), while the three-year balanced panel reveals significant increases in mortality offset by decreases in cost, both due primarily to redistribution. ${ }^{33}$

The less-consistent welfare implications for PTCA relative to CABG may be due to several factors. First, much of the effect is driven by simple redistribution and, as suggested by the change from the unbalanced to balanced panels, such patterns may depend substantially on the markets selected for analysis. In addition, these results may be affected by the limited mortality data available for PTCA. With only two years of observations, the hospital-specific coefficients used in the redistribution calculation are quite noisy. Finally, given the low average mortality rate for PTCA relative to CABG, one might question whether an outcome measure other than mortality might yield a more precise comparison of quality across hospitals.

A few caveats concerning these welfare calculations are worth noting. First, while the calculations described above capture the impact of business stealing, they do not include the effect of potential changes in the total market quantity of procedures. In a Cournot model, reductions in market quantity are associated with deadweight loss. Alternatively, one could imagine that volume-outcome effects, by changing the profitability of cardiac procedures for particular hospitals, could create incentives to increase or decrease volume. In the current setting, however, simply knowing whether the total volume of procedures increases or decreases does not allow for a definitive assessment of welfare effects. Specifically, the costs and benefits associated with the marginal procedure depend on the clinical condition of the patient receiving (or not

${ }^{33}$ One could use an analysis of quality-adjusted life years (QALYs) to determine whether the value of the life years lost in some models due to redistribution of PTCA patients outweighs the associated cost savings. Such calculations, however, require assumptions about the expected survival of those patients whose mortality was "accelerated" due to the redistribution and are beyond the scope of this paper. 
receiving) that treatment as well as the risk-adjusted outcome. These effects cannot be measured using the CSRS and CARS data as they do not include information on patients who were candidates for CABG or PTCA but did not receive either procedure. The welfare effect calculated in this paper thus should be viewed as an incremental effect beyond any impact that is due to the changes in the overall volume of cardiac procedures.

Second, this study examines only cardiac procedures and does not consider the effects of acquisitions on quality or cost in other clinical areas. Nevertheless, the methodology of this study could be applied to other types of complex treatment where volume-outcome effects may be present and a complementary relationship may exist between acquirers and targets.

Third, the welfare implications provided by this study rely on in-hospital mortality as an outcome measure. Ideally one would also like to examine other measures of quality, such as mortality or readmission within some fixed period after hospital discharge (e.g., 30 days or six months) or other measures of patient health status following a procedure. Such information, however, is not available in these data.

Finally, events other than acquisitions were occurring in New York during this period and may have affected the distribution of CABG and PTCA volume across hospitals. Of particular note is the release of hospital report cards for these procedures. Some studies have suggested that these report cards were associated with the shift of CABG volume from low-performing to high-performing hospitals (Mukamel and Mushlin, 1998; Cutler, Huckman, and Landrum, 2004). Others suggest that the institution of CABG report cards encouraged providers to operate on less severe patients (Dranove et al., 2003). To the extent that poor performing hospitals were more likely to 
engage in such risk selection, volume may have been redistributed between low and high performers. While it is possible that the results of this study could be confounded with the impact of report cards, I note the significant redistribution of CABG patients in the full sample (Table 3, Column 1) is not associated with redistribution effects on mortality (Table 6, Column 1).

\section{CONCLUSION}

This paper views hospital acquisitions as transactions that bring together complements—not simply substitutes—in production. When consolidation is viewed from this vertical perspective, its welfare effects must be assessed not solely by using standard relationships between measures of market concentration and market outcomes, but rather based on empirical analysis of the redistribution of volume between firms. Based on the sample of transactions from New York, I find that acquirers steal business within target markets. Though the welfare implications are somewhat more precise for CABG than for PTCA patients, hospital consolidation appears to have had relatively little impact on average cost and quality of major cardiac procedures in New York.

This study suggests that an overall assessment of the implications of hospital consolidation should consider the fact that these transactions do not simply reduce the number of firms providing substitute products. Rather, with respect to certain services, they alter the allocation of customers across firms with differentiated levels of quality and cost. Acknowledging the complementary nature of the hospitals involved in many 
acquisitions makes for a more complete assessment of consolidation's impact on the productivity of medical care. 


\section{REFERENCES}

American Hospital Association (1992). Hospital Mergers and Consolidations: 19801991, Chicago: American Hospital Association.

Appleby, Julie (2002). “Hospitals Fight for Turf in Medical Arms Race,” USA Today, February 20, pp. 1-2.

Baker, Laurence and Martin Brown (1999). "Managed Care, Consolidation Among Health Care Providers, and Health Care: Evidence From Mammography,” Rand Journal of Economics, 30(2), pp. 351-374.

Barro, Jason and David Cutler (2000). "Consolidation in the Medical Marketplace: A Case Study from Massachusetts,” in Steven Kaplan, ed., Mergers and Productivity, Chicago: University of Chicago Press.

Bates, David et al. (1997). “Coronary Angiography and Angioplasty After Acute Myocardial Infarction,” Annals of Internal Medicine, 126(7), pp. 539-550.

Bertrand, Marianne, Esther Duflo, and Sendhil Mullainathan (2004). "How Much Should We Trust Differences-in-Differences Estimates?” Quarterly Journal of Economics, 119(1), pp. 249-275.

Blustein, Jan (1993). "High-Technology Cardiac Procedures: The Impact of Service Availability on Service Use in New York State,” Journal of the American Medical Association, 270(3), pp. 344-349.

Capron, Laurence (1999). “The Long-Term Performance of Horizontal Acquisitions,” Strategic Management Journal, 20, pp. 987-1018.

Center for the Evaluative Clinical Sciences (1998). The Dartmouth Atlas of Health Care in the United States, 1998, Chicago: American Hospital Association.

Cutler, David and Jill Horwitz (2000). "Converting Hospitals from Not-for-Profit to ForProfit Status: Why and What Effects?” in David Cutler, ed., The Changing Hospital Industry: Comparing Not-for-Profit and For-Profit Institutions, Chicago: University of Chicago Press.

Cutler, David and Robert Huckman (2003). "Technological Development in Medical Care: The Diffusion of Angioplasty in New York State," Journal of Health Economics, 22(2), pp. 187-217.

Cutler, David, Robert Huckman, and Mary Beth Landrum (2004). “The Role of Information in Medical Markets: An Analysis of Publicly Reported Outcomes in Cardiac Surgery," American Economic Review Papers and Proceedings, 94(2), pp. 342-346. 
Cutler, David and Elizabeth Richardson (1999). "Your Money and Your Life: The Value of Health and What Affects It,” NBER Working Paper 6895.

Cutler, David, Mark McClellan, and Joseph Newhouse (2000). “How Does Managed Care Do It?” Rand Journal of Economics, 31(3), pp. 526-548.

Dierickx, Ingmar and Karel Cool (1989). “Asset Stock Accumulation and Accumulation of Competitive Advantage,” Management Science, 35(12), pp. 1504-1511.

Dranove, David, Daniel Kessler, Mark McClellan, and Mark Satterthwaite (2003). "Is More Information Better? The Effects of 'Report Cards' on Health Care Providers," Journal of Political Economy, 111(3), pp. 555-588.

Dranove, David and Richard Ludwick (1999). "Competition and Pricing by Nonprofit Hospitals: A Reassessment of Lynk's Analysis,” Journal of Health Economics, 18, pp. 87-98.

Dranove, David and Mark Shanley (1995). “Cost Reductions or Reputation Enhancement as Motives for Mergers: The Logic of Multihospital Systems,” Strategic Management Journal, 16, pp. 55-74.

Every, Nathan et al. (1993). “The Association Between On-Site Cardiac Catheterization Facilities and the Use of Coronary Angiography After Acute Myocardial Infarction,” New England Journal of Medicine, 329(8), pp. 546-551.

Farley, Dean and Ronald Ozminkowski (1992). "Volume-Outcome Relationships and Inhospital Mortality: The Effect of Changes in Volume Over Time,” Medical Care, 30(1), pp. 77-94.

Gaynor, Martin and Deborah Haas-Wilson (1999). "Change, Consolidation, and Competition in Health Care Markets,” Journal of Economic Perspectives, 13(1), pp. 141164.

Greater New York Hospital Association (1993-1997). Annual surveys of health care delivery systems in New York State.

Gresenz, Carol, Jeannette Rogowski, and José Escarce (2004). "Updated Variable-Radius Measures of Hospital Competition," Health Services Research, 39(2), pp. 417-430.

Hannan, Edward et al. (1991). “Coronary Artery Bypass Graft Surgery: The Relationship Between Inhospital Mortality Rate and Surgical Volume After Controlling for Clinical Risk Factors,” Medical Care, 29(11), pp. 1094-1107. 
Hannan, Edward et al. (1997). "Coronary Angioplasty Volume-Outcome Relationships for Hospitals and Cardiologists,” Journal of American Medical Association, 277(11), pp. 892-898.

Ho, Vivian (2000). "Evolution of the Volume-Outcome Relation for Hospitals Performing Coronary Angioplasty,” Circulation, 101(15), pp. 1806-1811.

Ho, Vivian and Barton Hamilton (2000). "Hospital Mergers and Acquisitions: Does Market Consolidation Harm Patients?” Journal of Health Economics, 19, pp. 767-791.

Keeler, Emmett, Glenn Melnick, and Jack Zwanziger (1999). “The Changing Effects of Competition on Non-Profit and For-Profit Hospital Pricing Behavior," Journal of Health Economics, 18, pp. 69-86.

Kessler, Daniel and Mark McClellan (2000). "Is Hospital Competition Socially Wasteful?” Quarterly Journal of Economics, pp. 577-615.

Kowalczyk, Liz (2003). "Heart Stent's New Promise May Be Costly for Hospitals,” Boston Globe, February 9, p. A1.

Luft, Harold, J.P. Bunker, and Alain Enthoven (1979). "Should Operations be Regionalized? The Empirical Relation Between Surgical Volume and Mortality” New England Journal of Medicine, 301(25), pp. 1364-1369.

Luft, Harold, Sandra Hunt, and Susan Maerki (1987). “The Volume-Outcome Relationship: Practice-Makes-Perfect or Selective-Referral Patterns?” Health Services Research, 22(2), pp. 157-182.

Lynk, William (1995). “The Creation of Economic Efficiencies in Hospital Mergers,” Journal of Health Economics, 14(5), pp. 507-530.

Mankiw, N. Gregory and Michael Whinston (1986). "Free Entry and Social Inefficiency,” Rand Journal of Economics, 17(1), pp. 48-58.

McClellan, Mark (1993). “The Economics of Medical Treatment Intensity,” Ph.D. Dissertation, Massachusetts Institute of Technology.

McClellan, Mark and Joseph Newhouse (1997). "The Marginal Cost-Effectiveness of Medical Technology: A Panel Instrumental-Variables Approach,” Journal of Econometrics, 77, pp. 39-64.

Melnick, Glenn et al. (1992). “The Effects of Market Structure and Bargaining Position on Hospital Prices,” Journal of Health Economics, 11, pp. 217-233.

Modern Healthcare (1994-2000). Annual surveys of hospital merger activity. 
Mukamel, Dana and Alvin Mushlin (1998). "An Analysis of Market Share and Price Changes After Publication of the New York State Cardiac Surgery Mortality Reports.” Medical Care, 36(7), pp. 945-54.

New York State Department of Health (2004). Certificate of Need Application Distributed (http://www.health.state.ny.us/nysdoh/cons/distributed_cons.htm, accessed August 15, 2004). (1998). Coronary Artery Bypass Surgery in New York State: 1994-1996.

Noether, Monica (1988). "Competition Among Hospitals," Journal of Health Economics, 7, pp. 259-284.

Organization for Economic Cooperation and Development (1999). OECD Health Data 99 database.

Peteraf, Margaret (1993). "The Cornerstones of Competitive Advantage: A ResourceBased View,” Strategic Management Journal, 14, pp. 179-191.

Phibbs, Ciaran and James Robinson (1993). "A Variable-Radius Measure of Local Hospital Market Structure," Health Services Research, 28(3), pp. 313-324.

Shen, Yu-Chu (2003). "Changes in Hospital Performance After Ownership Conversions,” Inquiry, 40(3), pp. 217-234.

Showstack, Jonathan et al. (1987). "Association of Volume with Outcome of Coronary Artery Bypass Graft Surgery: Scheduled vs. Nonscheduled Operations," Journal of the American Medical Association, 257(6), pp. 785-789.

Tolley, George, Donald Kenkel and Robert Fabian, eds. (1994). Valuing Health for Policy: An Economic Approach, Chicago: University of Chicago Press.

Tu, Jack et al. (1997). "Use of Cardiac Procedures and Outcomes in Elderly Patients with Myocardial Infarction in the United States and Canada," New England Journal of Medicine, 336(21), pp. 1500-1505.

Wernerfelt, Birger (1984). “A Resource-Based View of the Firm,” Strategic Management Journal, 5, pp. 171-180. 
Figure 1: Hospital Consolidations in New York State, 1992-1999

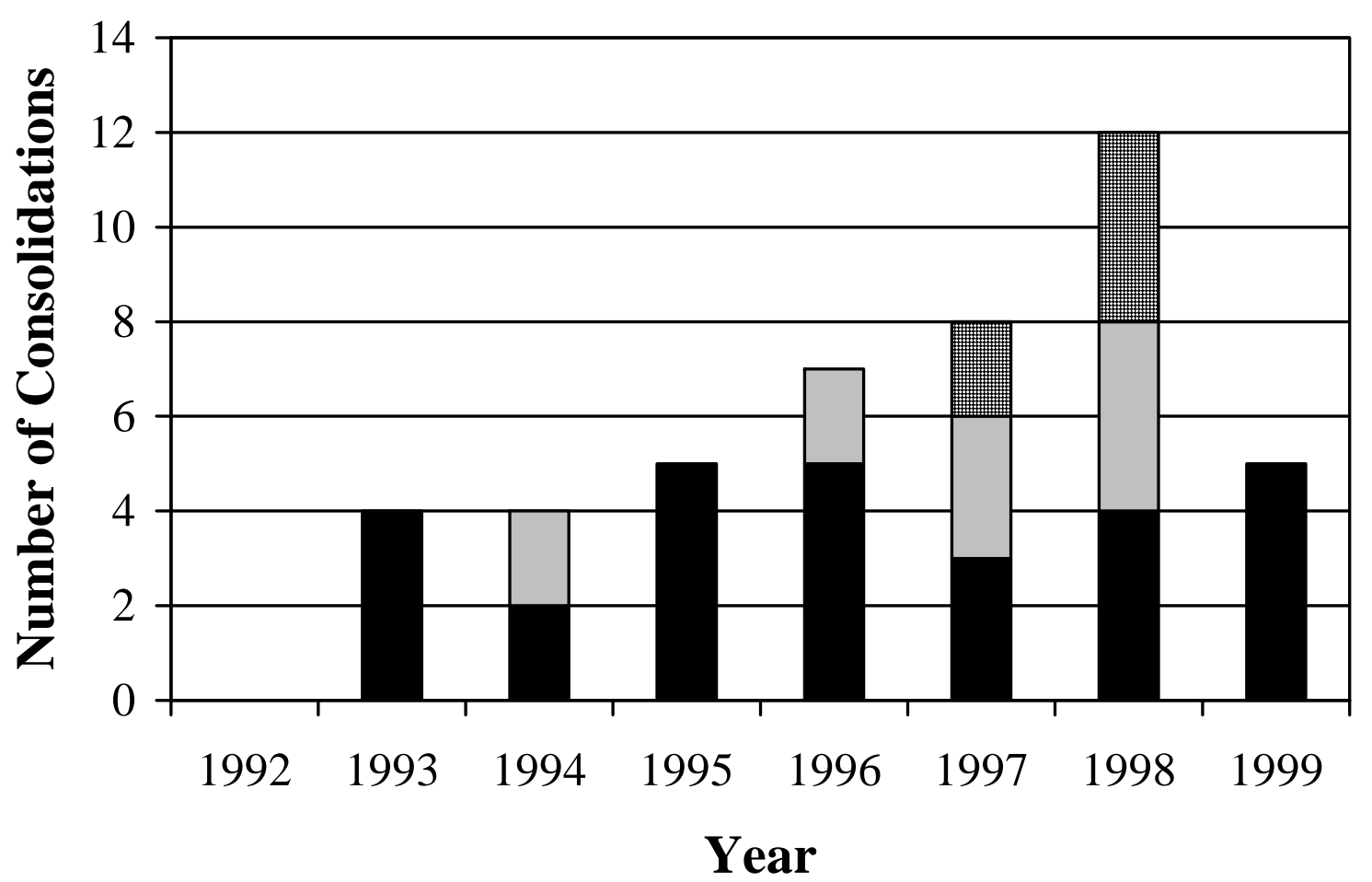

Acquisitions (Big-Small)

$\square$ Mergers (Small-Small)

Dergers (Big-Big)

Note: A hospital is considered "big" if it offers CABG and PTCA procedures and "small" if it does not offer these procedures. Transactions involving the acquisition of multiple target facilities are counted as single consolidations.

Sources: LEXIS-NEXIS search of local newspapers; Modern Healthcare; author correspondence with hospital executives. 


\section{Figure 2: Share to Acquirer Surrounding Acquisition Events}

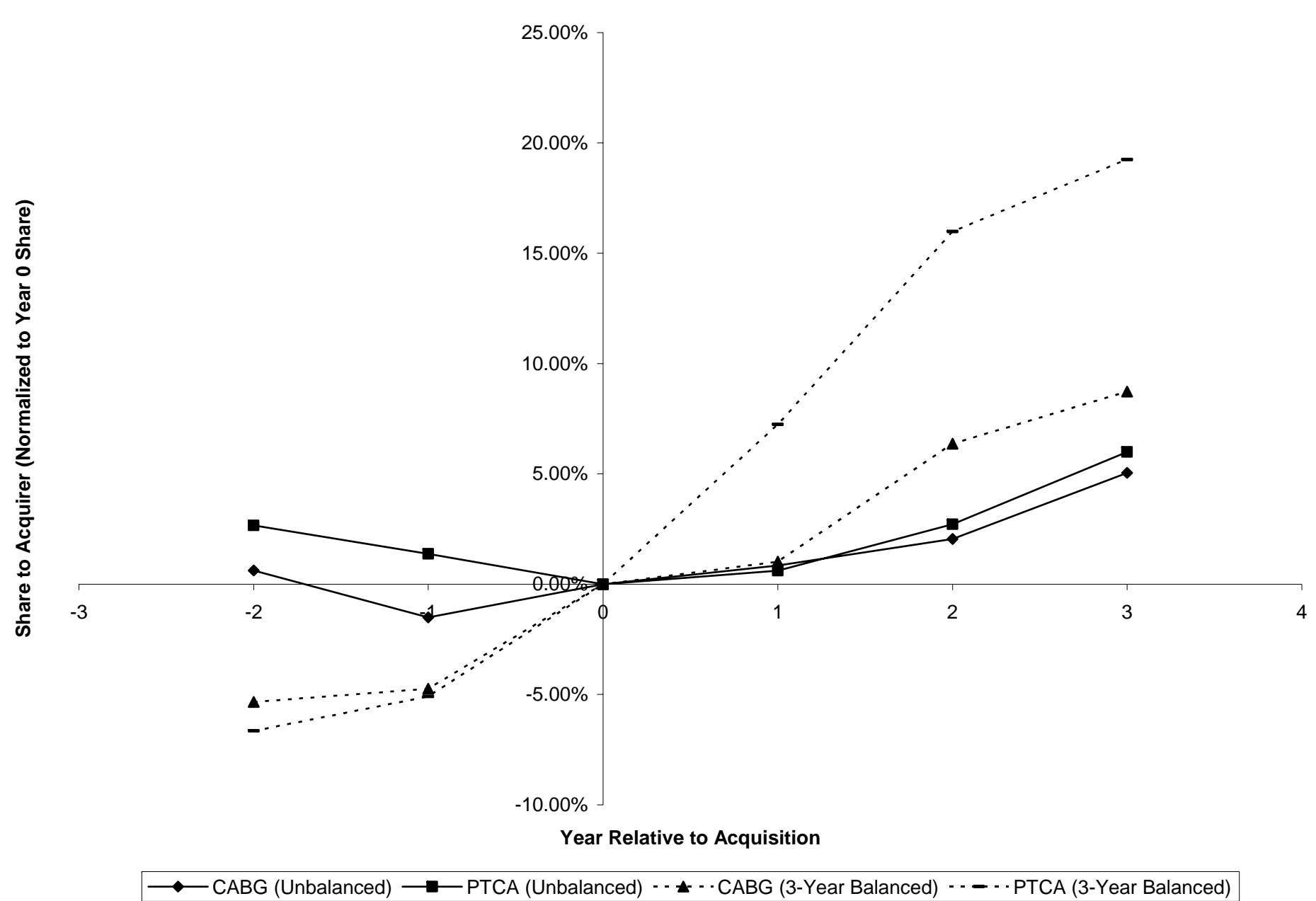

Note: Values for the unbalanced panels are obtained by subtracting the Year 0 coefficient from the relevant "year relative to merger" coefficient from Table 3 , Columns 1 and 2 .

Source: SPARCS Database, 1992-1998. 
Table 1: Estimated Revenues and Profits from CABG and PTCA Procedures for New York Hospitals, 1997

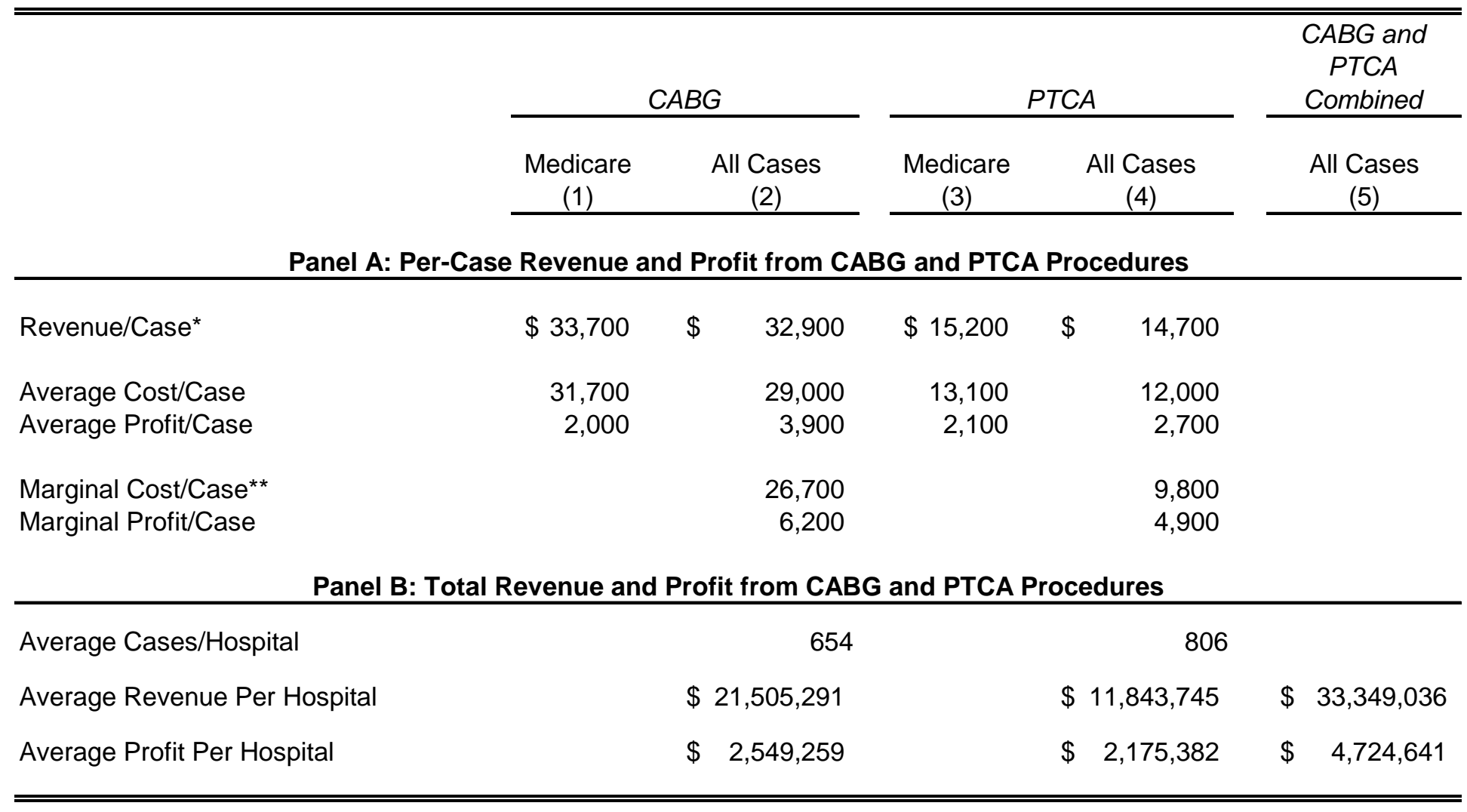

* Medicare revenue/case based on the assumption of \$6,164 per case mix adjusted admission. "All Cases" revenue figures assume that revenue/case is 10\% greater for Commercial patients and 20\% less for HMO and Medicaid patients (relative to Medicare). Further, the "All Cases" revenue assumes a payor mix similar to that in New York during 1997. For CABG this mix is 50\% Medicare, 25\% commercial, and 25\% Medicaid or HMO; for PTCA, this mix is 40\% Medicare, 30\% commercial, and 30\% Medicaid or HMO.

** The marginal cost figures are based on the estimated effect of In[annual CABG (PTCA) admissions] for hospital $h$ on average cost per CABG (PTCA) admission at hospital $h$ (see Equation (3)). The marginal cost estimates are calculated by dividing the growth in total costs due to a $1 \%$ increase in volume by the absolute magnitude of the $1 \%$ volume increment. 
Table 2: Descriptive Statistics for Acquirers and Targets in Sample, 1992

\begin{tabular}{|c|c|c|c|c|c|c|c|}
\hline & \multicolumn{3}{|c|}{ ACQUIRERS } & \multicolumn{3}{|c|}{ "TARGETS } & \\
\hline & $N$ & Mean & $\begin{array}{l}\text { Standard } \\
\text { Deviation }\end{array}$ & $N$ & Mean & $\begin{array}{l}\text { Standard } \\
\text { Deviation }\end{array}$ & \\
\hline Inpatient Beds & 16 & 856 & 318 & 31 & 421 & 158 & *** \\
\hline Inpatient Days & 16 & 269,759 & 96,635 & 31 & 125,084 & 55,111 & *** \\
\hline \multicolumn{8}{|l|}{ Financial Data (\$000s Unless Otherwise Specified) } \\
\hline Hospital Charges & 16 & $\$ 521,000$ & $\$ 253,000$ & 31 & $\$ 173,000$ & $\$ 90,300$ & $\star * *$ \\
\hline Net Revenue (Hospital Charges Less Discounts) & 16 & 363,000 & 175,000 & 31 & 121,000 & 64,800 & *** \\
\hline Operating Expenses & 16 & 403,000 & 204,000 & 31 & 126,000 & 68,700 & $\star * *$ \\
\hline Net Income Margin & 16 & $-0.9 \%$ & $3.6 \%$ & 31 & $0.9 \%$ & $3.6 \%$ & * \\
\hline Cost-to-Charge Ratio (Operating Expenses/Total Charges) & 16 & $77.1 \%$ & $9.9 \%$ & 31 & $72.9 \%$ & $8.9 \%$ & \\
\hline \multicolumn{8}{|l|}{ Patients Receiving } \\
\hline CABG & 15 & 649 & 361 & & & & \\
\hline PTCA & 16 & 469 & 302 & & & & \\
\hline
\end{tabular}

Note: ${ }^{* \star *}, \star \star$, and * denote that acquirer and target means are significantly different at the 1\%, 5\%, and 10\% levels, repsectively. Acquirer and target data are reported by facility (rather than by firm) in cases where a each facility reports data separately to Medicare. One acquirer provided PTCA but not CABG.

Source: Medicare PPS Cost Reports, 1992; New York State Department of Health, Statewide Planning and Research Cooperative System (SPARCS), 1992. 
Table 3: Acquirer Market Share in Target Markets

\begin{tabular}{|c|c|c|}
\hline & \multicolumn{2}{|c|}{ Market Share to Acquirer } \\
\hline & $\frac{\mathrm{CABG}}{\mathrm{(1)}}$ & $\frac{\text { PTCA }}{1(2)}$ \\
\hline \multicolumn{3}{|l|}{ Primary Market of Target $\mathrm{x}$} \\
\hline 4+ Years Pre-Acquisition & $\begin{array}{l}-0.035 \\
(0.028)\end{array}$ & $\begin{array}{r}-0.002 \\
(0.043)\end{array}$ \\
\hline 3 Years Pre-Acquisition & $\begin{array}{l}-0.032 \\
(0.020)\end{array}$ & $\begin{array}{r}-0.025 \\
(0.029)\end{array}$ \\
\hline 2 Years Pre-Acquisition & $\begin{array}{l}-0.017^{\# \neq} \\
(0.015)\end{array}$ & $\begin{array}{r}-0.030 \\
(0.025)\end{array}$ \\
\hline 1 Year Pre-Acquisition & $\begin{array}{r}-0.038 \\
(0.016)\end{array}$ & $\begin{array}{r}-0.043 \\
(0.021)\end{array}$ \\
\hline Year of Acquisition & $\begin{array}{r}-0.023 \\
(0.013)\end{array}$ & $\begin{array}{l}-0.057 \\
(0.017)\end{array}$ \\
\hline 1 Year Post-Acquisition & $\begin{array}{r}-0.015 \\
(0.016)\end{array}$ & $\begin{array}{r}-0.050 \\
(0.017)\end{array}$ \\
\hline 2 Years Post-Acquisition & $\begin{array}{l}-0.0033^{¥ \neq} \\
(0.014)\end{array}$ & $\begin{array}{r}-0.029 \\
(0.018)\end{array}$ \\
\hline 3 Years Post-Acquisition & 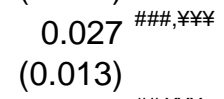 & $\begin{array}{l}0.003^{\# \# \#, \#} \\
(0.012)\end{array}$ \\
\hline 4+ Years Post-Acquisition & $\begin{array}{c}0.025^{\# \#, ¥ \# \#} \\
(0.015)\end{array}$ & $\begin{array}{l}0.0066^{\# \# \#, ¥ \neq} \\
(0.017)\end{array}$ \\
\hline \multicolumn{3}{|l|}{ Female (As Percentage of CABG } \\
\hline Cases) & $\begin{array}{r}0.042 \\
(0.027)\end{array}$ & $\begin{array}{r}0.031 \\
(0.047)\end{array}$ \\
\hline HMO (As Percentage of CABG Cases) & $\begin{array}{r}-0.046 \\
(0.059)\end{array}$ & $\begin{array}{l}-0.018 \\
(0.070)\end{array}$ \\
\hline $\begin{array}{l}\text { Medicaid (As Percentage of CABG } \\
\text { Cases) }\end{array}$ & $\begin{array}{r}0.011 \\
(0.084)\end{array}$ & $\begin{array}{r}0.045 \\
(0.099)\end{array}$ \\
\hline $\begin{array}{l}\text { Average Value of Dependent Variable } \\
\text { Prior to First Acquisition }\end{array}$ & 0.276 & 0.247 \\
\hline $\bar{N}$ & 111 & 111 \\
\hline NT & 997 & 997 \\
\hline Adjusted $\mathrm{R}^{2}$ & 0.909 & 0.894 \\
\hline Durbin-Watson Statistic & 1.64 & 1.50 \\
\hline
\end{tabular}

******** Coefficient is statistically significantly different from zero at the $1 \%, 5 \%$, and $10 \%$ levels, respectively.

Coefficient is statistically significantly different from the "Year of Acquisition" coefficient at the 1\%, 5\%, and 10\% levels, respectively.

$¥ ¥ ¥ ; \neq, \quad$ Coefficient is statistically significantly different from the "1 Year Pre-Acquisition" coefficient at the 1\%, 5\%, and 10\% levels, respectively.

Note: $\quad$ Robust standard errors, clustered by target market, are in parentheses. Each regression includes the following variables which do not appear in this table: a constant term; 3-year fixed effects; zip-code fixed effects; and indicators for several age categories (i.e., less than 50, 50-59, 60-64, 65-74, 75-84, and greater than 84). The data for each zip-code observation is weighted by the number of cases from that zip code. For ease of presentation, the indicators of significant differences from zero $\left({ }^{* * *}, * \star, *\right)$ are not presented for any of the "year relative to acquisition" variables. 
Table 4: Acquirer Market Share in Target Markets (Balanced Panel)

\begin{tabular}{|c|c|c|c|c|}
\hline & $\begin{array}{c}\text { CABG } \\
\text { Share to } \\
\text { Acquirer } \\
(1)\end{array}$ & $\begin{array}{c}\text { CABG } \\
\text { Share to } \\
\text { Acquirer } \\
(2)\end{array}$ & $\begin{array}{c}\text { PTCA } \\
\text { Share to } \\
\text { Acquirer } \\
(3)\end{array}$ & $\begin{array}{c}\text { PTCA } \\
\text { Share to } \\
\text { Acquirer } \\
(4)\end{array}$ \\
\hline \multicolumn{5}{|l|}{ Primary Market of Target $\mathrm{x}$} \\
\hline 2 Years Pre-Acquisition & $\begin{array}{l}0.00648 \\
(0.0326)\end{array}$ & $\begin{array}{l}-0.05340 \\
(0.0161)\end{array}$ & $\begin{array}{l}0.00622 \\
(0.0306)\end{array}$ & $\begin{array}{r}-0.06650 \\
(0.0448)\end{array}$ \\
\hline $\begin{array}{l}1 \text { Year Pre-Acquisition } \\
\text { Year of Acquisition }\end{array}$ & $\begin{array}{l}0.01359 \\
(0.0252)\end{array}$ & $\begin{array}{r}-0.04743 \\
(0.0295)\end{array}$ & $\begin{array}{l}0.01347 \\
(0.0118)\end{array}$ & $\begin{array}{l}-0.05097^{\star \star *} \\
(0.0170)\end{array}$ \\
\hline 1 Year Post-Acquisition & $\begin{array}{l}0.00381 \\
(0.0182)\end{array}$ & $\begin{array}{l}0.01022 \\
(0.0272)\end{array}$ & $\begin{array}{l}0.03140 \\
(0.0210)\end{array}$ & $\begin{array}{l}0.07234^{* \star x, \# \neq ¥} \\
(0.0272)\end{array}$ \\
\hline 2 Years Post-Acquisition & $\begin{array}{l}0.07411 \text { ***** } \\
(0.0249)\end{array}$ & $\begin{array}{l}0.06364 \\
(0.0259)\end{array}$ & 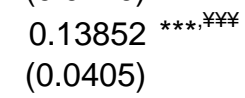 & $\begin{array}{l}0.15983^{\star \star \star,}, ¥ \neq ¥ \\
(0.0441)\end{array}$ \\
\hline 3 Years Post-Acquisition & & $\begin{array}{l}0.08734^{*, ; \# \#} \\
(0.0420)\end{array}$ & & $\begin{array}{l}0.19241^{\star \star \star}, ¥ \neq \neq \neq \\
(0.0535)\end{array}$ \\
\hline \multicolumn{5}{|l|}{ Female (As Percentage of CABG } \\
\hline Cases) & $\begin{array}{l}0.03086 \\
(0.0639)\end{array}$ & $\begin{array}{l}0.06908 \\
(0.1142)\end{array}$ & $\begin{array}{l}0.02116 \\
(0.0888)\end{array}$ & $\begin{array}{r}-0.06516 \\
(0.0751)\end{array}$ \\
\hline \multicolumn{5}{|l|}{ HMO (As Percentage of CABG } \\
\hline Cases) & $\begin{array}{r}-0.11301 \\
(0.1513)\end{array}$ & $\begin{array}{l}0.00565 \\
(0.1883)\end{array}$ & $\begin{array}{r}-0.22401 \\
(0.1803)\end{array}$ & $\begin{array}{r}-0.19988 \\
(0.2508)\end{array}$ \\
\hline \multicolumn{5}{|l|}{ Medicaid (As Percentage of CABG } \\
\hline Cases) & $\begin{array}{r}-0.01071 \\
(0.2231)\end{array}$ & $\begin{array}{l}0.05242 \\
(0.1791)\end{array}$ & $\begin{array}{r}-0.05868 \\
(0.2007)\end{array}$ & $\begin{array}{l}-0.59240 * \\
(0.3119)\end{array}$ \\
\hline \multicolumn{5}{|l|}{ Average Value of Dependent } \\
\hline $\begin{array}{l}\mathrm{N} \\
\mathrm{NT}\end{array}$ & $\begin{array}{c}36 \\
180\end{array}$ & $\begin{array}{c}18 \\
108\end{array}$ & $\begin{array}{c}35 \\
175\end{array}$ & $\begin{array}{c}17 \\
102\end{array}$ \\
\hline Adjusted $\mathrm{R}^{2}$ & 0.916 & 0.930 & 0.902 & 0.922 \\
\hline
\end{tabular}

$\star \star \star, \star *, * \quad$ Coefficient is statistically signficantly different from zero at the $1 \%, 5 \%$, and $10 \%$ levels, respectively.

$¥ ¥ ¥, ¥ ¥, ¥ \quad$ Coefficient is statistically signficantly different from the "1 Year Pre-Acquisition" coefficient at the 1\%, 5\%, and 10\% levels, respectively.

Note: Robust standard errors, clustered by target market, are in parentheses. Each regression includes the following variables which do not appear in this table: a constant term; 3-year fixed effects; zip-code fixed effects; and indicators for several age categories (i.e., less than 50, 50-59, 60-64, 65-74, 75-84, and greater than 84). The data for each zipcode observation is weighted by the number of cases from that zip code. 


\section{Table 5: Fixed-Effect Regressions of Procedure Mortality and Cost on Volume and Other Covariates}

\begin{tabular}{|c|c|c|c|c|}
\hline & $\begin{array}{c}\text { CABG } \\
\text { Mortality, } \\
1992-96 \\
(1) \\
\end{array}$ & $\begin{array}{c}\text { CABG } \\
\text { Cost, } \\
1993-98 \\
(2) \\
\end{array}$ & $\begin{array}{c}\text { PTCA } \\
\text { Mortality, } \\
\text { 1994-95 } \\
(3) \\
\end{array}$ & $\begin{array}{c}\text { PTCA } \\
\text { Cost, } \\
1993-98 \\
(4) \\
\end{array}$ \\
\hline In(Lagged Annual CABG Cases at Facility) & $\begin{array}{l}-0.0093 \text { ** } \\
(0.0047)\end{array}$ & $\begin{array}{l}-2,297 \text { *** } \\
(577.8)\end{array}$ & & \\
\hline In(Lagged Annual PTCA Cases at Facility) & & & $\begin{array}{r}0.0096 \\
(0.0082)\end{array}$ & $\begin{array}{l}-2,200 \text { *** } \\
(211.5)\end{array}$ \\
\hline Patient Age & $\begin{array}{l}-0.0044 \\
(0.0005)\end{array}$ & $\begin{array}{l}-932 \text { *** } \\
(73.2)\end{array}$ & $\begin{array}{l}-0.0016 \text { *** } \\
(0.0003)\end{array}$ & $\begin{array}{l}-373^{* \star \star} \\
(21.9)\end{array}$ \\
\hline (Patient Age) $)^{2} / 100$ & $\begin{array}{l}0.0041 \text { *** } \\
(0.0004)\end{array}$ & $\begin{array}{l}1,032 \quad * * * \\
(57.3)\end{array}$ & $\begin{array}{l}0.0015 \text { *** } \\
(0.0003)\end{array}$ & $\begin{array}{l}375 \\
(17.8)\end{array}$ \\
\hline Hospital Fixed Effects? & Yes & Yes & Yes & Yes \\
\hline Year Fixed Effects? & Yes & Yes & Yes & Yes \\
\hline Clinical Risk Covariates? & Yes & No & Yes & No \\
\hline $\mathrm{N}$ & $89,359^{¥}$ & 110,177 & $40,114^{¥}$ & 116,556 \\
\hline Adjusted $\mathrm{R}^{2}$ & 0.067 & 0.118 & 0.122 & 0.137 \\
\hline
\end{tabular}

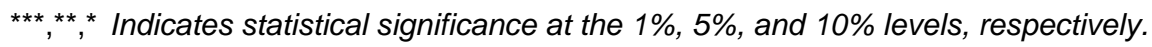

* The total number of CABG cases in the CSRS database for the years from 1992 through 1996 is 90,130. Subtracting the 771 records with a missing value for at least one covariate yields the total number of 89,359 included in the regression. For PTCA, the total number of cases in the CARS data for 1994 and 1995 is 40,265. Subtracting the 151 cases missing at least one covariate yields the total of 40,114.

Note: Results in Columns 1 and 3 are based on data from the CSRS and CARS databases. Results in Columns 2 and 4 are based on discharge data from SPARCS and cost data from Medicare PPS Cost Reports. Column 2 excludes cases with total charges less than \$5,000, and Column 3 excludes cases with total charges less than $\$ 2,500$. Robust standard errors are in parentheses. Each regression includes a constant term which is not reported in this table. 
Table 6: Calculation of Approximate Annual Change in Total Mortality and Cost for CABG and PTCA Due to All New York Acquisitions, 1992-1999

\begin{tabular}{|c|c|c|c|}
\hline & \multirow{2}{*}{$\begin{array}{c}\text { Full Sample } \\
\text { To } 3 \text { Years } \\
\text { Post- } \\
\text { Acquisition } \\
\end{array}$} & \multicolumn{2}{|c|}{ Balanced Panel } \\
\hline & & $\begin{array}{c}\text { To } 2 \text { Years } \\
\text { Post- } \\
\text { Acquisition } \\
\end{array}$ & $\begin{array}{c}\text { To } 3 \text { Years Post } \\
\text { Acquisition } \\
\end{array}$ \\
\hline CABG & & & \\
\hline Simple Redistribution & & & \\
\hline Change in Mortality & - & -3.50 & - \\
\hline Change in Cost & - & - & - \\
\hline Volume-Outcome Effects & & & \\
\hline Change in Mortality & -0.01 & -0.02 & -0.03 \\
\hline Change in Cost & $-\$ 2,249$ & $-\$ 4,935$ & $-\$ 6,828$ \\
\hline Total Change in Mortality & -0.01 & -3.52 & -0.03 \\
\hline Total Change in Cost & $-\$ 2,249$ & $-\$ 4,935$ & $-\$ 6,828$ \\
\hline
\end{tabular}

\section{PTCA}

Simple Redistribution

Change in Mortality

Change in Cost

Volume-Outcome Effects

Change in Mortality

Change in Cost

$-\$ 4,892$

$-\$ 23,929$

$-\$ 45,812$

Total Change in Mortality

4.16

0.00

5.99

Total Change in Cost

Note: Calculations represent total changes across all acquisitions in New York from 1992 through 1999. Figures are based on coefficients from versions of (1) with hospital-specific quality and cost intercepts, respectively, as the dependent variable (for simple redistribution) and Table 5 (for volume-outcome effects). Data on the average annual volume of procedures at local acquirers, non-local acquirers, and non-acquirers is for 2000. Dashes denote cases where the relevant coefficients used to calculate values are not statistically significant at better than the $10 \%$ level. 


\section{Appendix: Clinical Covariates Included in CABG and PTCA Mortality Regressions}

\begin{tabular}{|c|c|c|c|}
\hline Variable & Description & $\begin{array}{c}\text { In CABG } \\
\text { Mortality Regression? }\end{array}$ & $\begin{array}{c}\text { In PTCA } \\
\text { Mortality Regression? }\end{array}$ \\
\hline IS92 & Dummy for year=1992 & Yes & No \\
\hline IS93 & Dummy for year=1993 & Yes & No \\
\hline IS94 & Dummy for year=1994 & Yes & Yes \\
\hline IS95 & Dummy for year=1995 & Yes & Yes \\
\hline IS96 & Dummy for year=1996 & Yes & No \\
\hline AGE & Patient age & Yes & Yes \\
\hline AGEQUAD & $(A G E)^{2} / 100$ & Yes & Yes \\
\hline ETHNIC & Dummy for Hispanic & Yes & No \\
\hline BSA & Body surface area & Yes & Yes \\
\hline ANGINA & Angina: CCS functional class & Yes & Yes \\
\hline NORISK & Dummy for no pre-operative risk factors & Yes & No \\
\hline MI 24HR & Dummy for MI within previous 24 hours & Yes & Yes \\
\hline MI_WEEK & Dummy for MI within previous 1-7 days & Yes & Yes \\
\hline PREVMI & Dummy for any previous $\mathrm{MI}$ & Yes & Yes \\
\hline MORE1MI & Dummy for more than 1 previous $\mathrm{MI}$ & No & Yes \\
\hline TRNSMMI & Dummy for transmural MI & Yes & Yes \\
\hline STROKE & Dummy for stroke & Yes & Yes \\
\hline CAROCERB & Dummy for carotid/cerebrovascular disease & Yes & Yes \\
\hline AORTO & Dummy for aortoiliac disease & Yes & Yes \\
\hline FEM_POP & Dummy for femoral/popliteal & Yes & Yes \\
\hline UNST̄ABLE & Dummy for hemodynamic instability & Yes & Yes \\
\hline SHOCK & Dummy for shock & Yes & Yes \\
\hline HYPTENS & Dummy for hypertension history & Yes & Yes \\
\hline IV NTG & Dummy for IV NTG within 24 hours of operation & Yes & Yes \\
\hline LVENTHT & Dummy for left ventricular hypertrophy & Yes & Yes \\
\hline MALVENAR & Dummy for malignant ventricular arrhythmia & Yes & Yes \\
\hline CHOBPUDS & Dummy for chronic obstructive pulmonary disease & Yes & Yes \\
\hline CPB & Dummy for cardiopulmonary bypass at start of procedure & No & Yes \\
\hline EXCAASAO & Dummy for extensively calcified ascending aorta & Yes & No \\
\hline DIABETES & Dummy for diabetes requiring medication & Yes & Yes \\
\hline IMSYSTDF & Dummy for immune system deficiency & Yes & Yes \\
\hline IABPPREO & Dummy for IABP pre-op & Yes & Yes \\
\hline ERDXCATH & Dummy for emergency transfer to OR after cath & Yes & No \\
\hline ERPTCA & Dummy for emergency transfer to OR after PTCA & Yes & No \\
\hline PREVCAAD & Dummy for previous PTCA, this admission & Yes & Yes \\
\hline CABEFORE & Dummy for PTCA before this admission & Yes & Yes \\
\hline THROMB & Dummy for thrombolytic therapy within 7 days & Yes & Yes \\
\hline SMOK2WK & Dummy for smoking history in past 2 weeks & Yes & Yes \\
\hline SMOK1YR & Dummy for smoking history in past year & No & Yes \\
\hline FEMALE & Dummy for female & Yes & Yes \\
\hline NONWHT & Dummy for non-white & Yes & Yes \\
\hline EMERGNCY & Dummy for emergency surgical priority & Yes & No \\
\hline EJFR20 & Dummy for ejection fraction less than $20 \%$ & Yes & Yes \\
\hline EJFR2029 & Dummy for ejection fraction $20-29 \%$ & Yes & Yes \\
\hline EJFR3039 & Dummy for ejection fraction $30-39 \%$ & Yes & Yes \\
\hline LMT & Dummy for left main trunk, $50 \%$ or greater & Yes & Yes \\
\hline PLAD & Dummy for Prox LAD or Maj Diag, $70 \%$ or greater & Yes & Yes \\
\hline MDLAD & Dummy for Mid/Dist LAD or Maj Diag, $70 \%$ or greater & Yes & Yes \\
\hline $\mathrm{RCA}$ & Dummy for RCA or PDA, $70 \%$ or greater & Yes & Yes \\
\hline LCX & Dummy for LCA or Large Marg, $70 \%$ or greater & Yes & Yes \\
\hline LESION B & Dummy for Lesion Type B & No & Yes \\
\hline LESIONC & Dummy for Lesion Type C & No & Yes \\
\hline $\mathrm{CHF}$ & Dummy for congestive heart failure & Yes & Yes \\
\hline RENFAIL & Dummy for renal failure & Yes & Yes \\
\hline PREVOHS & Dummy for previous open heart operations & Yes & Yes \\
\hline POSSTR & Dummy for positive stress test & No & Yes \\
\hline
\end{tabular}

Note:

Regressions also include In(lagged annual procedure volume) and hospital fixed effects. The CAC provides the following caveat with respect to the use of the indicator for chronic obstructive pulmonary disease (COPD): "Prior to 1993 , the definition used for COPD was considered subjective, and irregular frequency distributions across institutions were noted. The definition was changed in 1993 to include documentation of objective clinical criteria. However, the wide range in COPD rates reported across hospitals remains, presumably due to practice patterns among various providers with regard to utilizing objective testing for COPD." 
